\title{
Evaluasi Kriteria Kerusakan Tanah untuk Produksi Biomassa pada Lahan Kering di Kabupaten Subang
}

\author{
Budy Frasetya Taufik Qurrahman'1, Abraham Suriadikusumah'2, Rachmat Haryanto ${ }^{2}$ \\ 1) Alumni Program Studi Magister Ilmu Tanah, Fakultas Pertanian, Universitas Padjadjaran. \\ 2) Staff Pengajar Fakultas Pertanian, Universitas Padjadjaran \\ Koresponden : budyftq1682@gmail.com
}

\begin{abstract}
Government Regulation No. 150 Year 2000 on Soil Degradation Control for Production of Biomass is a testament to the seriousness of the government in anticipating and addressing land degradation due to biomass production. In fact, unsustainable intensification can cause soil degradation. Soil degradation parameters may change in accordance with the conditions of the district/city. This study aimed to evaluate the standard criteria of soils degradation on dry land in Subang District. Did having high accuracy and whether the ten parameters are decisive parameters. The research method used was a descriptive survey. Data from the field and then analyzed using discriminant analysis. The results of discriminant analysis for soil degradation standard criteria in Subang District, determining parameters were selected 4 parameters, ie bulk density, sand fraction, electrical conductivity, soil reaction $(\mathrm{pH})$ with the level of accuracy obtained discriminant function $74,1 \%$ with corelation coeficient 0,866 or $86,6 \%$ and determination coeficient (R2) 0,75 or $75 \%$.
\end{abstract}

Keywords: Accuracy Discriminant Function, Evaluation Standards Criteria, Parameters Determinant

\section{PENDAHULUAN}

Kriteria baku kerusakan tanah telah ditetapkan oleh pemerintah melalui Peraturan Pemerintah (PP) Nomor 150 Tahun 2000 Tentang Pengendalian Kerusakan Tanah untuk Produksi Biomassa. Tata cara pengukuran kriteria baku kerusakan tanah untuk produksi biomassa telah diatur dalam Peraturan Menteri Negara Lingkungan Hidup (Permenlh) No. 07 Tahun 2006. Berdasarkan Bab III pasal 5 ayat 2 PP No. 150 Tahun 2000, kriteria baku kerusakan tanah yang telah ditetapkan oleh pemerintah bersifat tidak mutlak dan dapat ditinjau kembali sekurang-kurangnya lima tahun sekali.

Seiring meningkatnya permintaan komoditas pertanian, perkebunan dan hasil hutan, ketersediaan lahan untuk meningkatkan produksi semakin berkurang akibat adanya konversi lahan. Intensifikasi pertanian, perkebunan dan hutan produksi merupakan pilihan logis untuk meningkatkan produksi ditengah upaya ekstensikasi yang semakin sulit. Pengelolaan lahan dan penggunaan lahan secara berlebihan untuk produksi komoditas pertanian dan hutan produksi dapat menyebabkan kerusakan tanah sehingga dapat menurunkan mutu dan fungsinya (KEMENLH, 2009).

Kerusakan tanah sifatnya dinamis dengan banyak faktor yang mempengaruhi, sehingga diperlukan penilaian kerusakan tanah secara berkala. Selain itu evaluasi terhadap kriteria baku kerusakan tanah sangat diperlukan untuk mengetahui apakah kriteria-kriteria tersebut akurat dan mampu memberikan gambaran kondisi aktual. Penelitian ini merupakan upaya untuk mengevaluasi 10 kriteria kerusakan tanah. Evaluasi dilakukan terhadap akurasi hasil penetapan kerusakan tanah yang dibandingkan dengan kondisi aktual di lapangan.

\section{BAHAN DAN METODE}

Penelitian ini dilaksanakan pada bulan September sampai dengan Oktober 2014. Lokasi penelitian meliputi wilayah administrasi Kabupaten Subang.

Bahan yang digunakan meliputi: peta Rupa Bumi Indonesia (RBI) skala 1:25.000, peta curah hujan skala 1:100.000, peta tanah Skala 1:100.000, peta kemiringan lereng skala $1: 100.000$, peta penggunaan lahan skala 1:100.000, peta Rencana Tata Ruang Wilayah (RTRW) Kabupaten Subang Skala 1:100.000 (BAPPEDA Kabupaten Subang, 2011). Petapeta tersebut digunakan untuk penetapan unit lahan dengan cara tumpang susun (overlay).

Peralatan yang digunakan meliputi Global Positioning System (GPS), pisau, klinometer, cangkul, meteran, sekop, ring sampler, kantong plastik, bor tanah, dan kamera digital. 
Peralatan yang digunakan untuk analisis data meliputi satu unit komputer, software Arcgis 9.3 dan SPSS Versi 19.

Metode penelitian yang digunakan adalah metode survey deskriptif. Penentuan lokasi sampling tanah dilakukan secara purposive sampling. Lokasi sampling ditetapkan berdasarkan potensi kerusakan pada setiap penggunaan lahan.

Pada tahap survey lapang dilakukan pengamatan terhadap sifat tanah yang meliputi: ketebalan solum dan kebatuan permukaan. Pada tahap ini juga dilakukan pengambilan contoh pada masing-masing unit lahan. Contoh tanah yang diambil meliputi contoh tanah terganggu dan tanah tidak terganggu.

Pengujian sifat kimia tanah $\left(\mathrm{pH}\left(\mathrm{H}_{2} \mathrm{O}\right)\right.$, potensial redoks, daya hantar listrik (DHL)) dilakukan di Laboratorium Pengujian Balai Penelitian Tanaman Sayuran, pengujian sifat fisika tanah (permeabilitas, komposisi fraksi, porositas total, dan berat isi) dilakukan di Laboratorium Fisika Tanah Faperta UNPAD, dan pengujian jumlah mikroba dilakukan di Laboratorium Jurusan Agroteknologi UIN Bandung.

Tahapan selanjutnya adalah analisis data. Metode analisis yang digunakan adalah analisis diskriminan yang dihitung dengan menggunakan software analisis statistik SPSS Versi 19. Hasil seleksi parameter tahap pertama akan menghasilkan parameter terpilih yang layak untuk dilanjutkan analisis diskriminan tahap selanjutnya.

\section{HASIL DAN PEMBAHASAN}

Kabupaten Subang pada koordinat 107o 31'-107054' BT dan 6011'-6040'LS. Curah hujan rata-rata hasil analisis dengan metode poligon thiessen adalah $2.771 \mathrm{~mm} /$ tahun. Klasifikasi iklim menurut Oldeman termasuk B2. Luas areal penelitian meliputi $44.565,92$ Ha. Berdasarkan analisis peta tematik ditetapkan 27 titik contoh pewakil. Karakteristik fisik lokasi pengambilan sampel dapat dilihat pada Tabel 1.

Tabel 1 Data Lokasi Pengambilan Sampel Tanah

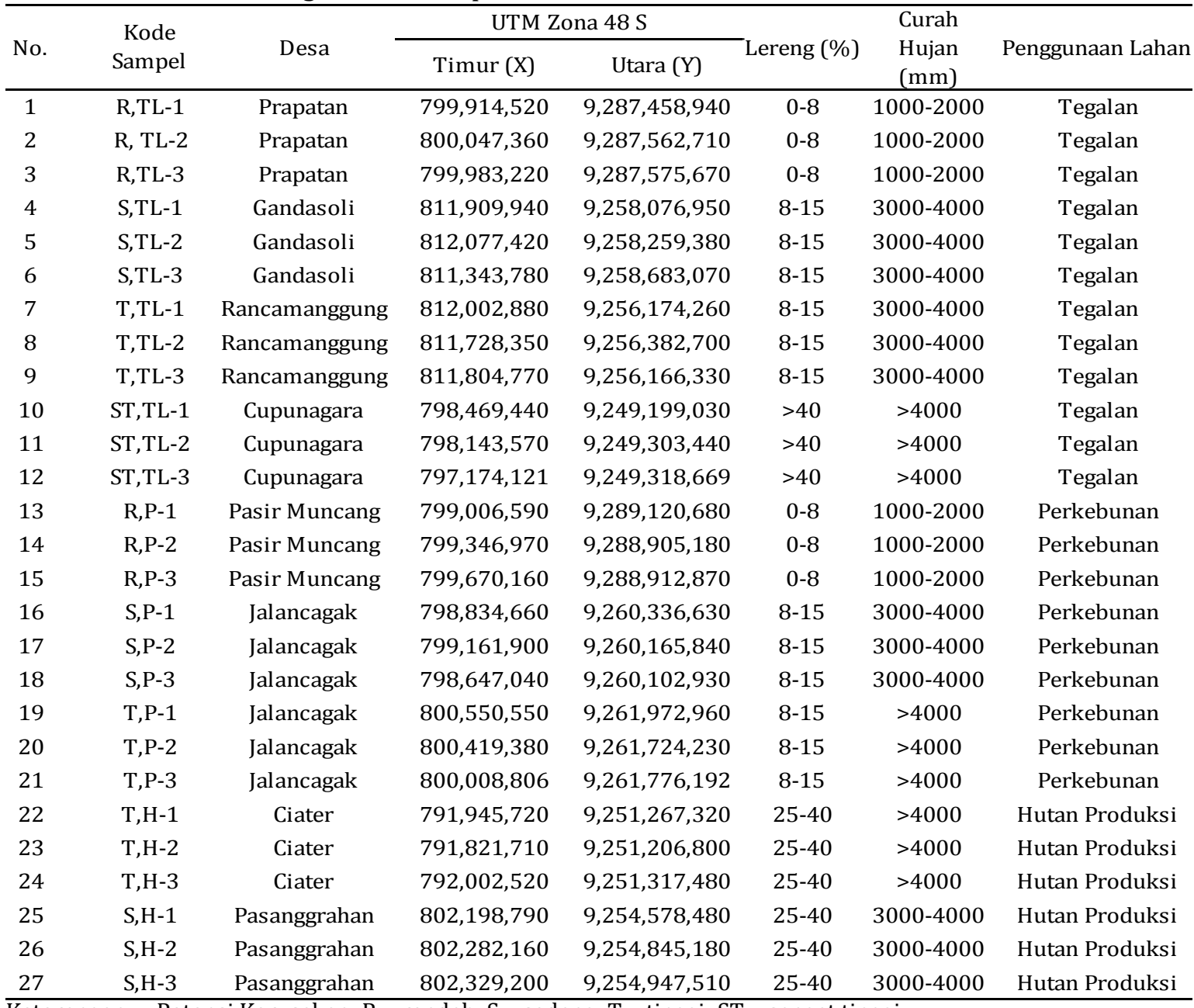

Keterangan: - Potensi Kerusakan: $\mathrm{R}=$ rendah; $\mathrm{S}$ = sedang; $\mathrm{T}$ = tinggi; $\mathrm{ST}$ = sangat tinggi

- Penggunaan lahan: $\mathrm{P}=$ perkebunan; $\mathrm{H}=$ hutan produksi; $\mathrm{TL}=$ tegalan 
Parameter penentu kerusakan tanah diperoleh dengan menggunakan metode analisis diskriminan. Analisis diskriminan dapat dilakukan apabila data yang diuji berdistribusi normal, oleh karena itu data masing-masing parameter ditransformasi ke bentuk $z$ score (Santoso, 2014). Hasil analisis diskriminan tahap pertama dapat dilihat pada Tabel 2 .

Tabel 2 Hasil Analisis Kelayakan Parameter Penentu dari Kemenlh Tahun 2006

\begin{tabular}{clcccc}
\hline No & \multicolumn{1}{c}{ Parameter } & Wilks' Lambda & $\mathrm{F}$ & Sig. & Kelayakan \\
\hline 1 & Ketebalan Solum & 0,491 & 7,935 & $\left.0,001^{*}\right)$ & Terpilih \\
2 & Bobot Isi & 0,422 & 10,519 & $\left.0,000^{*}\right)$ & Terpilih \\
3 & Permeabilitas & 0,703 & 3,242 & $\left.0,041^{*}\right)$ & Terpilih \\
4 & pH H $\mathrm{H}_{2} \mathrm{O}$ & 0,619 & 4,721 & $\left.0,010^{*}\right)$ & Terpilih \\
5 & Daya Hantar Listrik (DHL) & 0,616 & 4,784 & $\left.0,010^{*}\right)$ & Terpilih \\
6 & Potensial Redoks & 0,470 & 8,641 & $\left.0,001^{*}\right)$ & Terpilih \\
7 & Fraksi Pasir & 0,410 & 11,054 & $\left.0,000^{*}\right)$ & Terpilih \\
8 & Fraksi Liat & 0,505 & 7,514 & $\left.0,001^{*}\right)$ & Terpilih \\
9 & Kebatuan Permukaan & 0,809 & 1,804 & $0,174^{\mathrm{ns})}$ & Tidak Terpilih \\
10 & Porositas Total & 0,963 & 0,298 & $\left.0,827^{\mathrm{ns}}\right)$ & Tidak Terpilih \\
11 & Jumlah Populasi Mikroba & 0,747 & 2,598 & $0,077^{\mathrm{ns})}$ & Tidak Terpilih \\
\hline
\end{tabular}

Keterangan: ${ }^{*}$ S Signifikan pada taraf $5 \%$; ns) Tidak Signifikan pada taraf 5 \%.

Parameter kebatuan permukaan, porositas total, dan jumlah mikroba memiliki nilai Sig. $>0,05$, maka parameter tersebut tidak dapat digunakan untuk membedakan kategori kerusakan tanah. Berdasarkan analisis parameter, pada lahan kering yang memiliki kategori kerusakan sangat rendah, rendah, sedang, tinggi dan sangat tinggi tidak dipengaruhi oleh kebatuan permukaan, porositas total dan jumlah mikroba.

Penilaian selanjutnya dilakukan terhadap kelayakan parameter melalui pemodelan diskriminan. Hasil analisis diskriminan metode stepwise dapat dilihat pada Tabel 3.

Tabel 3 Nilai Persentase Keragaman Fungsi Diskriminan

\begin{tabular}{ccccc}
\hline Fungsi & Eigenvalue & $\begin{array}{c}\text { Keragaman } \\
(\%)\end{array}$ & $\begin{array}{c}\text { Kumulatif } \\
(\%)\end{array}$ & $\begin{array}{c}\text { Korelasi } \\
\text { Kanonikal }\end{array}$ \\
\hline 1 & 2,991 & 56,1 & 56,1 & 0,866 \\
2 & 1,996 & 37,4 & 93,5 & 0,816 \\
3 & 0,347 & 6,5 & 100,0 & 0,507 \\
\hline
\end{tabular}

Berdasarkan Tabel 3, fungsi pertama dengan nilai eigenvalue 2,99 mampu menjelaskan keragaman sebesar 56,1\% pada taraf 5 $\%$. Fungsi pertama dinilai mampu menjelaskan keragaman yang lebih baik jika disbandingkan dengan fungsi 2 dan 3 . Pengujian fungsi diskriminasi dengan Wilks' Lambda. (Tabel 4).
Tabel 4 Uji Fungsi Diskrminan dengan Wilks' Lambda

\begin{tabular}{ccccc}
\hline $\begin{array}{c}\text { Uji } \\
\text { Fungsi }\end{array}$ & $\begin{array}{c}\text { Wilks' } \\
\text { Lambda }\end{array}$ & $\begin{array}{c}\text { Chi- } \\
\text { square }\end{array}$ & df & Sig. \\
\hline 1 & 0,062 & 61,138 & 12 & 0,000 \\
2 & 0,248 & 30,688 & 6 & 0,000 \\
3 & 0,742 & 6,551 & 2 & 0,038 \\
\hline
\end{tabular}

Nilai wilks' Lambda untuk fungsi pertama dan fungsi kedua memiliki signifikansi ( sig. < 0,05). Berdasarkan nilai signifikansinya, fungsi 1 dan 2 mampu mendiskriminasikan dengan tingkat kepercayaan di atas $99 \%$ (Sitorus dkk., 2011). Hasil seleksi kelayakan terhadap 8 parameter diperoleh 4 parameter yang memenuhi kriteria analisis terpilih. Permeabilitas, ketebalan solum, daya hantar listrik dan fraksi liat tidak termasuk parameter penentu kerusakan tanah. Fungsi diskriminan yang diperoleh berdasarkan koefisien kanonikal baku fungsi diskriminan, yaitu:

$D_{1}=-10,334+5,996 X_{1}+2,213 X_{2}-0,40 X_{3}+$ $0,075 \mathrm{X}_{4}$

Dimana: $\mathrm{X}_{1}=$ Bobot Isi; $\mathrm{X}_{2}=\mathrm{pH} ; \mathrm{X}_{3}=$ Potensial Redoks $\mathrm{X}_{4}=\%$ Fraksi Pasir

Fungsi $D_{1}$ diperoleh dari nilai Wilk's Lambda sebesar 0,06 dengan signifikansi sebesar 0,00 jauh di bawah 0,05\%. Hal ini berarti fungsi $\mathrm{D}_{1}$ dapat digunakan untuk membedakan kelas kerusakan tanah. Fungsi $\mathrm{D}_{1}$ memiliki koefisien korelasi (r) sebesar 0,87 
dengan koefisien determinasi ( $\left.\mathrm{R}^{2}\right)$ 0,75 angka ini menunjukan bahwa $75 \%$ kelas kerusakan tanah dapat dijelaskan dengan fungsi $\mathrm{D}_{1}$. Hasil uji keterandalan memberikan gambaran bahwa parameter yang digunakan un-tuk penentuan status kerusakan tanah masih dapat digunakan walaupun nilai koefisien determinasinya baru mencapai $75 \%$.

Kerusakan tanah sangat tinggi diklasifikasikan secara tepat (100 \%). Ketepatan parameter yang terpilih dalam analisis diskriminan dari 6 sampel kerusakan tanah kelas "Rendah" 83,3 \% diklasifikasikan secara benar, kesalahan klasifikasi 16,7 \% masuk ke kategori sedang. Kerusakan tanah "sedang" diklasifikasikan secara benar 88,9\%, kesalahan klasifikasi 11,1\%, masuk kategori tinggi.
Kerusakan tanah kategori tinggi diklasifikasikan secara tepat 88,9 \%, kesalahan klasifikasi sebesar 11,1 \% sehingga termasuk ke dalam kategori sedang.

Berdasarkan penilaian ketepatan, diperoleh 8 parameter yang layak analisis. Parameter tersebut kemudian diseleksi kembali, sehingga terpilih 4 parameter penentu. Keterandalan fungsi diskriminan dalam mengelompokkan tingkat kerusakan tanah akurasinya baru mencapai 74,1 \%. Hasil uji dengan metode Leave-one-out cross validation (Santoso, 2014) disajikan pada Tabel 5. Berdasarkan nilai rata-rata ketelitian, tingkat akurasi hasil penelitian masih lebih rendah daripada nilai akurasi pada skala tinjau menurut Arsyad (2006) yaitu sebesar 75 \%.

Tabel 5 Hasil Uji Ketepatan Klasifikasi Parameter Penentu

\begin{tabular}{|c|c|c|c|c|c|c|}
\hline \multirow{2}{*}{$\begin{array}{c}\text { Pengelompokan } \\
\text { Hasil Validasi }\end{array}$} & \multirow{2}{*}{ Kerusakan Tanah } & \multicolumn{4}{|c|}{ Anggota Grup } & \multirow{2}{*}{ Total } \\
\hline & & Rendah & Sedang & Tinggi & Sangat Tinggi & \\
\hline \multirow{4}{*}{ Jumlah } & Rendah & 3 & 1 & 1 & 1 & 6 \\
\hline & Sedang & 0 & 8 & 1 & 0 & 9 \\
\hline & Tinggi & 0 & 2 & 6 & 1 & 9 \\
\hline & Sangat Tinggi & 0 & 0 & 0 & 3 & 3 \\
\hline \multirow{4}{*}{$\%$} & Rendah & 50,0 & 16,7 & 16,7 & 16,7 & 100,0 \\
\hline & Sedang & 0,0 & 88,9 & 11,1 & 0,0 & 100,0 \\
\hline & Tinggi & 0,0 & 22,2 & 66,7 & 11,1 & 100,0 \\
\hline & Sangat Tinggi & 0,0 & 0,0 & 0,0 & 100,0 & 100,0 \\
\hline \multicolumn{6}{|c|}{ Rata-rata Ketelitian Klasifikasi metode Leave-one-out cross validation } & $74,1 \%$ \\
\hline
\end{tabular}

Keanggotaan sampel masing-masing kategori kerusakan tanah setelah dikelompokkan dengan fungsi diskriminan dapat dilihat pada Tabel 6 .

Tabel 6 Keanggotaan Grup Sampel Berdasarkan Uji Ketepatan Klasifikasi

\begin{tabular}{|c|c|}
\hline $\begin{array}{l}\text { Kerusakan } \\
\text { Tanah }\end{array}$ & Anggota Grup Sampel \\
\hline Sangat Rendah & - \\
\hline Rendah & S,H-3; S,P-3; T,H-2 \\
\hline Sedang & $\begin{array}{l}\text { R,TL-3; S,H-1; S,H-2; S,P-1; } \\
\text { S,TL-1; S,TL-2; S,TL-3; ST,TL-1; } \\
\text { T,H-1; T,H- 3; T,P-1; T,P-2; } \\
\text { T,P-3 }\end{array}$ \\
\hline Tinggi & $\begin{array}{l}\text { R,P-3; R,TL-1; S,P-2; ST,TL-2; } \\
\text { ST,TL-3; T,TL-1; T,TL-2 }\end{array}$ \\
\hline Sangat Tinggi & R,P-1; R,P-2; R,TL-2; T,TL-3 \\
\hline $\begin{array}{l}\text { Keterangan: } \\
\text { - Potensi Kerusa } \\
\text { tinggi; ST = san } \\
\text { - Penggunaan la }\end{array}$ & $\begin{array}{l}\text { kan: } \mathrm{R}=\text { rendah; } \mathrm{S}=\text { sedang; } \mathrm{T} \\
\text { gat tinggi } \\
\text { han: } \mathrm{P}=\text { perkebunan; } \mathrm{H}=\text { hut } \\
\text { tegalan }\end{array}$ \\
\hline
\end{tabular}

\section{SIMPULAN}

Hasil seleksi parameter penentu kriteria kerusakan tanah terpilih 4 parameter penentu, yaitu: komposisi fraksi (fraksi pasir); daya hantar listrik, $\mathrm{pH}\left(\mathrm{H}_{2} \mathrm{O}\right)$ dan bobot isi.

Model persamaan diskriminan yang terbentuk adalah $D_{1}=-10,334+5,996 X_{1}+2,213$ $\mathrm{X}_{2}-0,40 \mathrm{X}_{3}+0,075 \mathrm{X}_{4}\left(\mathrm{r}=0,866 ; \mathrm{R}^{2}=0,749\right)$ dengan koefisien korelasi serempak 0,87 dan koefisien determinasi 0,75 atau $75 \%$.

\section{DAFTAR PUSTAKA}

Arsyad, S. 2006. Konservasi Tanah dan Air. IPB Press, Bogor.

Kementerian Lingkungan Hidup (KEMENLH). 2006. Peraturan Menteri Negara Lingkungan Nidup Nomor 07 Tahun 2006 Tentang Tata Cara Pengukuran Kriteria Baku Kerusakan Tanah Untuk Produksi Biomassa. Kementerian Lingkungan Hidup, Jakarta. 
Presiden Republik Indonesia. 2000. Peraturan Pemerintah Nomor 150 Tahun 2000 Tentang Pengendalian Kerusakan Tanah Untuk Produksi Biomasa. Sekretariat Negara Republik Indonesia, Jakarta.

Santoso, S. 2014. Analisis Statistik Multivariat Konsep dan Aplikasi dengan SPSS Edisi Revisi. Elex Media, Jakarta.
Sitorus, S. R. P., Susanto, B., Haridjaja, O. 2011. Kriteria dan klasifikasi tingkat degradasi lahan di lahan kering (studi kasus: lahan kering di Kabupaten Bogor). Jurnal Tanah dan Iklim, 34:66-8. 